\title{
CALIDAD DE PLÁNTULAS DE LECHUGA EN DIFERENTES VOLÚMENES DE CELDAS Y SU INFLUENCIA EN EL RENDIMIENTO
}

\author{
Fabricio Alejandro Salusso ${ }^{1}$, José Omar Plevich², Angel Ramón Sanchez Delgado ${ }^{3}$, Liliana Elida Grosso ${ }^{4}$, Diego \\ Fernando Ramos ${ }^{5}$
}

\begin{abstract}
RESUMEN
Con el objetivo de evaluar la calidad de plántulas obtenidas en bandejas de germinación de diferente volumen de celdas y su influencia sobre el rendimiento de un cultivo de lechuga durante dos ciclos de producción otoño-invernal, se sembró un cultivar tipo mantecosa (Lactuca sativa var. capitata) en un diseño completamente aleatorio. Los tratamientos fueron: $24 \mathrm{~cm}^{3} /$ celda (128 celdas/bandeja); $13 \mathrm{~cm}^{3} /$ celda (200 celdas/bandeja) y $7 \mathrm{~cm}^{3} /$ celda (288 celdas/ bandeja). Se evaluó número de hojas, longitud de raíces, altura de plántula, peso fresco y seco de la parte aérea y raíces hasta el momento del trasplante en campo efectuado a los 37 y 49 días después de la siembra para cada ciclo de producción. Los resultados mostraron diferencias significativas con un mayor número de hojas, longitud de raíces, altura de plántula, peso fresco y seco de la parte aérea y raíces para las plántulas obtenidas en celdas de 24 $\mathrm{cm}^{3}$ seguidas de las $13 \mathrm{~cm}^{3}$ y finalmente las de $7 \mathrm{~cm}^{3}$. La calidad de las plántulas de lechuga está relacionada con el volumen de celda de las bandejas de germinación, obteniéndose posteriormente mejores rendimientos.
\end{abstract}

Palabras-claves: bandejas de germinación, Lactuca sativa var. capitata, biomasa

\section{ABSTRACT \\ QUALITY LETTUCE SEEDLINGS IN DIFFERENT VOLUMES OF CELLS AND THEIR INFLUENCE ON YIELD}

In order to evaluate the quality of seedlings obtained in germination trays with different volumes of cells and their influence on the yield for a crop of lettuce for two production cycles autumn- winter, seeded cultivar type buttery (Lactuca sativa var. capitata) in a completely randomized design. The treatments were: $24 \mathrm{~cm}^{3} /$ cell (128 cell/tray); 13 $\mathrm{cm}^{3} /$ cell (200 cell/tray) y $7 \mathrm{~cm}^{3} /$ cell (288 cell/tray). Leaf number, root length, seedling height, fresh and dry weight of shoot and roots were evaluated until the time of transplantation in field made at 37 and 49 days after planting for each production cycle. The results showed significant differences with a greater number of leaves, root length, seedling height, fresh and dry weight of the aerial parts and roots of seedlings obtained in $24 \mathrm{~cm}^{3}$ cells followed by $13 \mathrm{~cm}^{3}$ and finally $7 \mathrm{~cm}^{3}$. The quality of the lettuce seedlings is related to the volume of the cell plug trays, yielding subsequently better yields.

Keywords: plug trays, Lactuca sativa var. capitata, biomass

\section{Recebido para publicação em 27/07/2015. Aprovado em 15/12/2015.}

1 - Ing. Agrónomo; Docente Producción Hortícola, FAV- U.N.R.C. (Argentina). fsalusso@ayv.unrc.edu.ar

2 - Ing. Agrónomo; Docente Dasonomía, FAV- U.N.R.C. (Argentina). oplevich@ayv.unrc.edu.ar

3 - Dr. En Ingeniería de Sistemas y Computación, Instituto de Ciencias Exactas, UFRRJ, Seropédica, Brasil. asanchez@ufrrj.br

4 - Ing. Agrónomo; Docente Producción Hortícola, FAV- U.N.R.C. (Argentina). 1grosso@ayv.unrc.edu.ar

5 - Ing. Agrónomo; Docente Producción Hortícola, FAV- U.N.R.C. (Argentina). dramos@ayv.unrc.edu.ar 


\section{INTRODUCCIÓN}

Dentro de las hortalizas de hoja, la lechuga (Lactuca sativa L.) es ampliamente conocida y cultivada en todos los países del mundo debido a su importancia alimenticia como fuente de vitaminas y sales minerales (SANTI et al. 2010). En Argentina, la lechuga es la principal hortaliza de hoja cultivada y consumida, representando el $49 \%$ del volumen total producido en el país con $33.000 \mathrm{t}$. (COFECYT, 2008). En el cinturón hortícola de Río Cuarto (Córdoba-Argentina) la lechuga constituye el cultivo más representativo dentro del grupo de hortalizas de hoja, cubriendo una superficie aproximada de 150 has y rendimientos promedios de $25 \mathrm{tha}^{-1}$.

Los cultivos hortícolas y florícolas pueden iniciarse de dos maneras, una de ellas es la siembra tradicional en la que se coloca la semilla en el suelo; otra es, comenzando el cultivo a partir de plántulas que luego se llevarán al terreno definitivo, una operación denominada trasplante. Cuando hablamos de plántulas, nos estamos refiriendo a una pequeña planta ya establecida, con hojas y un sistema radicular parcialmente desarrollado.

Al trasplantar una plántula a campo, estamos adelantando en tiempo el cultivo, factor muy importante para lograr producciones anticipadas. El cultivo a partir de plántulas es conveniente cuando las semillas son costosas, cuando queremos anticipar la producción, ahorrar mano de obra, cuando las temperaturas del suelo son elevadas para una rápida germinación de las semillas, o cuando las semillas son muy pequeñas y necesitan cuidados especiales para nacer (MINAMI, 1995; SILVA y KATHERINE, 2004).

En el mercado existen varios modelos de bandejas de germinación, con diferentes números de celdas, profundidades, volúmenes, formas y con la posibilidad de ser reutilizadas (MODOLO y NETO, 1999). Las bandejas de germinación con su diseño normalizado, fabricadas en polietileno especial, lisas, y con presencia de estrías, facilitan la extracción de las plántulas, permitiendo excelente drenaje y aireación radicular. Son de bajo costo de transporte, almacenamiento y se adaptan para todo tipo de máquinas sembradoras (MELLONI, 2012).

La variabilidad de modelos asociado a la utilización de determinados sustratos implican diferentes respuestas morfológicas y fisiológicas de las plántulas, influyendo en su calidad final, y su posterior desempeño en las etapas de cultivo en campo o invernadero (NESMITH y DUVAL, 1998). Una plántula de calidad es aquella que tiene un buen desarrollo radicular, un tallo vigoroso, con ausencia de clorosis, libre de plagas y enfermedades. Para superar un estrés de trasplante, debe tener una adecuada capacidad radicular para la absorción de agua y nutrientes, además de la capacidad de generación de nuevas raíces. La tasa de crecimiento es reducida cuando se utilizan plántulas de baja calidad (LESKOVAR, 2001).

La forma de la celda, redondas frente a piramidales, puede influir en el vigor y la supervivencia de la plántula. Las raíces podrían desarrollarse demasiado y enredarse en las celdas redondas, especialmente si las plántulas sufren condiciones ambientales no favorables. Cuando se tiene tamaños pequeños de celdas, este problema se torna más crítico, debido a la disminución de volumen para el crecimiento de las raíces (BENNETT, 2010). En general la elección del tamaño y la profundidad de celda está en función de la especie seleccionada, tiempo de crecimiento, sistema radicular y vegetativo. Si bien hay una relación directa entre el volumen de la celda y el tamaño de la plántula, por razones principalmente de costos, la tendencia es utilizar bandejas con mayor número de celdas y de menor volumen (MARQUES et al., 2003).

Muchos productores comerciales utilizan bandejas con un mayor número de celdas, esto permite aumentar el número de plántulas producidas por unidad de bandeja. No obstante, hay que considerar que los envases de menor volumen tienen mayores fluctuaciones de humedad, nutrientes, $\mathrm{O}_{2}, \mathrm{pH}$ y salinidad, siendo no muy claro cuál es la respuesta de las raíces al crecer en pequeños volúmenes y cuál es el comportamiento pos-trasplante de las plántulas en condiciones de cultivo (VAVRINA, 1995; LESKOVAR, 2001). En general, a medida que aumenta el volumen de celda aumenta el área foliar, la biomasa aérea y radical de las plántulas (CANTLIFFE, 1993).

Un óptimo crecimiento de las raíces de las plántulas depende de un sustrato favorable, 
agua, fertilidad y espacio físico de enraizamiento (LESKOVAR et al., 1990). Un pequeño espacio disponible para las raíces, dificulta el normal suministro de recursos para garantizar un crecimiento y desarrollo óptimo (MENEZES et al., 2000). El delicado equilibrio entre raíces y parte aérea puede alterarse cuando el sistema de raíces se restringe a un pequeño volumen de celda, y el desequilibrio resultante puede tener a corto plazo, así como a largo plazo, efectos en el rendimiento del cultivo.

A medida que se alcanza con mayor rapidez el número de hojas adecuado para el trasplante se reduce el tiempo de permanencia en la bandeja y con ello se logran reducir múltiples factores que afectan la calidad final de las plántulas, como riesgo de ocurrencia de enfermedades, ataques de plagas, envejecimiento, problemas de restricción radicular, costos de producción, entre otros (LESKOVAR, 2001).

En el cinturón hortícola de Río Cuarto (Córdoba-Argentina), la producción de plántulas en bandejas de germinación a desplazado al empleo de almácigos o siembra directa en la iniciación de determinados cultivos, siendo la lechuga la principal hortaliza de hoja que se realiza empleando éste método de producción durante todo el año. A pesar de la implicancia que tiene el volumen de las celdas sobre la calidad de la plántula y su respuesta productiva posterior, se utiliza un tamaño de celda de $7 \mathrm{~cm}^{3}$ y existe escasa información sobre cuál debería ser el volumen más adecuado a utilizar. En este trabajo procuramos mostrar que la calidad de las plántulas de lechuga determinada por la biomasa aérea y radicular, está relacionada positivamente con el volumen de celda de las bandejas de germinación, traduciéndose posteriormente en mejores rendimientos del cultivo al momento de la cosecha.

\section{MATERIAL Y MÉTODOS}

\section{Descripción del área de estudio}

El ensayo se realizó en el área experimental de la Universidad Nacional de Río Cuarto $\left(33^{\circ}\right.$ 07' Latitud Sur; $64^{\circ} 14^{\prime}$ Longitud Oeste; 421 m.s.n.m.), Córdoba (Argentina), durante dos ciclos de producción otoño-invernal. El suelo del sitio es de textura franco arenoso, clasificado como Haplustol típico y de actitud agrícola (CANTERO GUTIÉRREZ et al., 1986). La precipitación media anual es de $801 \mathrm{~mm}$, con un régimen de tipo monzónico. La zona presenta una marcada amplitud térmica, con temperaturas inferiores a $0{ }^{\circ} \mathrm{C}$ en los meses de Junio - Julio y por encima de $35^{\circ} \mathrm{C}$ en los meses de Diciembre - Enero. El período libre de heladas es de 256 días y se extiende de Septiembre a mediados de Mayo (ADESUR, 1999).

\section{Descripción del ensavo en el invernadero}

La siembra en bandejas se realizó el 04/04/2012 (ciclo 1) y 06/05/2014 (ciclo 2) en un invernadero tipo capilla de estructura metálica y cobertura de policarbonato, de $6 \mathrm{~m}$ de ancho, $20 \mathrm{~m}$ de largo y $4 \mathrm{~m}$ de altura a la cumbrera, con sistema de calefacción $\mathrm{y}$ ventilación forzados. La variedad de lechuga empleada fue tipo mantecosa (Lactuca sativa var. capitata). Los tratamientos fueron en bandejas de germinación de: $24 \mathrm{~cm}^{3} /$ celda (128 celdas/bandeja); $13 \mathrm{~cm}^{3} /$ celda (200 celdas/bandeja) y $7 \mathrm{~cm}^{3} /$ celda (288 celdas/bandeja). El sustrato utilizado fue turba Sphagnum y aditivos. Las bandejas permanecieron en el invernadero hasta el trasplante recibiendo riegos diarios en forma manual.

El diseño experimental fue completamente aleatorio con cuatro repeticiones. La unidad experimental se correspondió con el tamaño de cada bandeja $(54,5 \mathrm{~cm}$ x $28 \mathrm{~cm})$, siendo éste uniforme para todas las bandejas. Para la evaluación se extrajo una muestra al azar de 20 plántulas al momento del trasplante para cada tratamiento. Las muestras se lavaron sobre un tamiz para eliminar el sustrato adherido y se colocaron sobre una escala graduada para determinar la altura de la misma $(\mathrm{cm})$, la cual se midió desde la inserción de las hojas en el cuello de la plántula hasta el extremo apical de las mismas y la longitud de raíces $(\mathrm{cm})$, desde la inserción de la primera raíz hasta el extremo distal de las mismas. Por otra parte, se determinó el número de hojas, considerando solo aquellas que se encontraban totalmente desplegadas.

Para la determinación de la biomasa aérea y radicular, se cortaron las plántulas en la base de 
inserción de las hojas y se evaluó el peso verde y seco de la parte aérea y raíces (g). Para determinar el peso seco, las muestras se llevaron a estufa a 70 ${ }^{\circ} \mathrm{C}$ durante 48 horas aproximadamente, hasta lograr peso constante.

\section{Descripción del ensayo en campo}

El trasplante en campo se realizó a los 37 y 49 días después de la siembra para el ciclo 1 y 2 respectivamente, cuando las plántulas alcanzaron de 4 a 6 hojas verdaderas. El diseño experimental fue en bloques completos al azar con tres tratamientos correspondientes a las bandejas de germinación $\left(24,13\right.$ y $7 \mathrm{~cm}^{3} /$ celda) y tres repeticiones, en un total de nueve parcelas experimentales, cuyas dimensiones fueron de 2,10 m x 1,75 m. En cada parcela se trasplantaron 42 plantas en un marco de plantación de $0,35 \mathrm{~m}$ entre hileras y $0,25 \mathrm{~m}$ entre plantas. Todos los tratamientos fueron protegidos con manta térmica cuya densidad fue de $17 \mathrm{~g} . \mathrm{m}^{-2}$.

El sistema de riego fue por goteo, constituido por una tubería de polietileno ubicada en la cabecera de las líneas de plantación en la cual se colocaron cintas de riego con goteros distanciados a $0,10 \mathrm{~m}$ mediante el uso de conectores. El caudal de los goteros fue de $0,85 \mathrm{~L} . \mathrm{h}^{-1}$. La frecuencia de riego se determinó cuando el agua útil en los primeros 50 $\mathrm{cm}$ del perfil se reducía hasta un $60 \%$ de su valor.

La cosecha del cultivo se realizó a los 127 y 105 días después del trasplante para el ciclo 1 y 2 respectivamente, recolectando 20 plantas centrales de cada parcela y se evaluó peso fresco y seco de la parte aérea $(\mathrm{g})$ y rendimiento $\left(\mathrm{t} \mathrm{ha} \mathrm{H}^{-1}\right)$. Las muestras se llevaron a estufa a $70{ }^{\circ} \mathrm{C}$ durante 48 horas aproximadamente, hasta lograr peso constante.

\section{Análisis estadísticos}

Los datos se analizaron estadísticamente con el programa Infostat (DI RIENZO et al., 2014), aplicando ANAVA y análisis de comparación de medias con el test de LSD Fisher $(\mathrm{p} \leq 0,05)$.

\section{RESULTADOS Y DISCUSIONES}

\section{$\underline{N^{\circ} \text { de hojas }}$}

Las diferencias observadas al momento del trasplante, mostraron una tendencia positiva en relación al número de hojas en las plántulas desarrollados en bandejas con celdas de mayor volumen de sustrato, el aumento en la disponibilidad de recursos y espacio físico para la exploración de las raíces, produjo una respuesta positiva en el crecimiento de las mismas, logrando alcanzar un mayor número de hojas y en menor tiempo en las bandejas con celdas de $24 \mathrm{~cm}^{3}$, seguidos por los obtenidos en $13 \mathrm{~cm}^{3}$ y por último los obtenidos en $7 \mathrm{~cm}^{3}$ para ambos ciclos de producción (Cuadro 1).

Resultados similares obtuvieron Seabra et al. (2002) en lechuga evaluando los mismos volúmenes de celda. A medida que aumentó el tiempo de permanencia de las plántulas en las bandejas se observó un envejecimiento, manifiesto por un amarillamiento de las hojas basales, siendo esto con mayor intensidad en las celdas de menor volumen. Ante cualquier causa externa que retrase la operación de trasplante en el momento adecuado,

Cuadro 1. Número promedio de hojas al trasplante obtenidas en plántulas de lechuga mantecosa para diferentes volúmenes de celdas durante dos ciclos de producción.

\begin{tabular}{ccc}
\hline \multirow{2}{*}{ Volumen } & \multicolumn{2}{c}{$\mathrm{N}^{\circ}$ de hojas } \\
\cline { 2 - 3 } & $37 \mathrm{dds}$ & $49 \mathrm{dds}$ \\
\hline $24 \mathrm{~cm}^{3}$ & $6,00 \mathrm{a}$ & $5,50 \mathrm{a}$ \\
$13 \mathrm{~cm}^{3}$ & $5,30 \mathrm{~b}$ & $4,90 \mathrm{~b}$ \\
$7 \mathrm{~cm}^{3}$ & $5,00 \mathrm{~b}$ & $4,00 \mathrm{c}$ \\
\hline $\mathrm{r}^{2}$ & 0,27 & 0,68 \\
\hline $\mathrm{CV}$ & 13,3 & 9,32 \\
\hline$p$ value & 0,0138 & $<0,0001$ \\
\hline
\end{tabular}

Diferentes letras indican diferencias significativas según test de LSD Fisher $(\mathrm{p} \leq 0,05)$ 
las plántulas producidas en celdas de mayor volumen podrían permanecer más tiempo en la misma con menores riesgos de envejecimiento.

\section{Altura de plántulas}

La altura de las plántulas constituyó otra variable que respondió significativamente a la variación en el volumen de las celdas. En ambos ciclos de producción se logró una mayor altura a medida que se incrementó el volumen. Las diferencias encontradas fueron estadísticamente significativas, siendo éstas de mayor magnitud principalmente en el primer ciclo, en esta situación las plántulas desarrollados en celdas de $24 \mathrm{~cm}^{3}$ duplicaron la altura respecto a los obtenidos en celdas de $7 \mathrm{~cm}^{3}$, el valor promedio fue de $12,95 \mathrm{~cm}$ en contraste con los $6,54 \mathrm{~cm}$ obtenido en celdas de menor volumen, un valor intermedio de $9,11 \mathrm{~cm}$ se obtuvo en celdas de $13 \mathrm{~cm}^{3}$ (Cuadro 2).

Los resultados que se obtuvieron a trasplante confirman las afirmaciones de diversos autores, que manifiestan como un mayor volumen de celdas aumenta el desarrollo del área foliar de las plántulas (LESKOVAR et al,. 1990; CANTLIFFE, 1993; MENEZES et al., 2000).

\section{Longitud de raíces}

Al analizar la longitud de raíces de las plántulas se observaron diferencias significativas con un menor crecimiento en bandejas con celdas de 7 $\mathrm{cm}^{3}$ respecto a los otros volúmenes. En cambio, al contrastar los resultados obtenidos en celdas de 13 $\mathrm{cm}^{3}$ y $24 \mathrm{~cm}^{3}$, los valores fueron similares en los dos ciclos de producción (Cuadro 3).

La reducción del volumen de celdas implicó una reducción de la capacidad para el almacenamiento de agua y nutrientes disponibles para las raíces, además la celda en sí misma constituyó una barrera física limitando la exploración de las raíces. En este sentido, y en concordancia con lo manifestado por

Cuadro 2. Altura promedio de plántulas de lechuga mantecosa al trasplante obtenidas para diferentes volúmenes de celdas durante dos ciclos de producción.

\begin{tabular}{ccc}
\hline \multirow{2}{*}{ Volumen } & \multicolumn{2}{c}{ Altura de plántulas $(\mathrm{cm})$} \\
\cline { 2 - 3 } & $37 \mathrm{dds}$ & $49 \mathrm{dds}$ \\
\hline $24 \mathrm{~cm}^{3}$ & $12,95 \mathrm{a}$ & $7,65 \mathrm{a}$ \\
$13 \mathrm{~cm}^{3}$ & $9,11 \mathrm{~b}$ & $6,66 \mathrm{~b}$ \\
$7 \mathrm{~cm}^{3}$ & $6,54 \mathrm{c}$ & $4,36 \mathrm{c}$ \\
\hline $\mathrm{r}^{2}$ & 0,76 & 0,68 \\
\hline $\mathrm{CV}$ & 16,58 & 16,07 \\
\hline$p$ value & $<0,0001$ & $<0,0001$
\end{tabular}

Diferentes letras indican diferencias significativas según test de LSD Fisher $(\mathrm{p} \leq 0,05)$

Cuadro 3. Longitud promedio de raíces de lechuga mantecosa al trasplante obtenidas para diferentes volúmenes de celdas durante dos ciclos de producción.

\begin{tabular}{ccc}
\hline \multirow{2}{*}{ Volumen } & \multicolumn{2}{c}{ Longitud de raíces $(\mathrm{cm})$} \\
\cline { 2 - 3 } & $37 \mathrm{dds}$ & $49 \mathrm{dds}$ \\
\hline $24 \mathrm{~cm}^{3}$ & $14,34 \mathrm{a}$ & $10,15 \mathrm{a}$ \\
$13 \mathrm{~cm}^{3}$ & $14,03 \mathrm{a}$ & $9,93 \mathrm{a}$ \\
$7 \mathrm{~cm}^{3}$ & $9,12 \mathrm{~b}$ & $7,99 \mathrm{~b}$ \\
\hline $\mathrm{r}^{2}$ & 0,39 & 0,23 \\
\hline $\mathrm{CV}$ & 25,34 & 19,96 \\
\hline$p$ value & 0,0013 & 0,029
\end{tabular}

Diferentes letras indican diferencias significativas según test de LSD Fisher $(\mathrm{p} \leq 0,05)$ 
Leskovar (2001), pudo observarse que a medida que las plántulas permanecieron más tiempo en las celdas, las raíces comienzan a crecer en forma horizontal en la base de la misma, llegando a producirse una importante acumulación, siendo esto con mayor intensidad en aquellas plántulas que crecieron en celdas de $7 \mathrm{~cm}^{3}$.

Un menor volumen de sustrato disponible sumado a un mayor tiempo de permanencia de las plántulas en las bandejas aumentó considerablemente las probabilidades de restricción del crecimiento radicular, siendo ésta variable significativamente determinante de la calidad final de las plántulas (LESKOVAR et al., 1990; NESMITH y DUVAL, 1998; MENEZES et al., 2000). Un menor desarrollo del sistema radicular puede tener inferencia al momento del trasplante, ya que esta operación en sí misma implica un estrés para las plántulas, y si a ello se suman condiciones ambientales desfavorables, aquellas plántulas que posean un mejor desarrollo radicular, podrán sobrellevar de manera más adecuada esta etapa logrando una rápida implantación.

\section{Biomasa de las plántulas}

Los resultados mostraron una tendencia a lograr un mayor peso al trasplante de las plántulas obtenidas en bandejas con celdas de $24 \mathrm{~cm}^{3}$, un desarrollo intermedio mostraron aquellos que crecieron en celdas de $13 \mathrm{~cm}^{3}$, y el menor desempeño se produjo en las celdas de $7 \mathrm{~cm}^{3}$, siendo las diferencias estadísticamente significativas al analizar el peso fresco de la parte aérea; sin embargo, no se encontraron diferencias en peso de raíces entre celdas de 24 y $13 \mathrm{~cm}^{3}$ (Cuadros 4 y 5).

Evidentemente, el aumento de las restricciones

Cuadro 4. Promedio del peso fresco de la parte aérea, raíces y total de las plántulas al trasplante, obtenidos para los diferentes volúmenes de celdas en los dos ciclos de producción.

\begin{tabular}{ccccccc}
\hline \multirow{2}{*}{ Volumen } & \multicolumn{2}{c}{$\begin{array}{c}\text { Peso fresco parte aérea } \\
(\mathrm{g})\end{array}$} & \multicolumn{2}{c}{$\begin{array}{c}\text { Peso fresco raíces } \\
(\mathrm{g})\end{array}$} & \multicolumn{2}{c}{$\begin{array}{c}\text { Peso fresco total } \\
(\mathrm{g})\end{array}$} \\
\cline { 2 - 7 } & $37 \mathrm{dds}$ & $49 \mathrm{dds}$ & $37 \mathrm{dds}$ & $49 \mathrm{dds}$ & $37 \mathrm{dds}$ & $49 \mathrm{dds}$ \\
\hline $24 \mathrm{~cm}^{3}$ & $2,54 \mathrm{a}$ & $1,16 \mathrm{a}$ & $0,47 \mathrm{a}$ & $0,41 \mathrm{a}$ & $3,01 \mathrm{a}$ & $1,58 \mathrm{a}$ \\
$13 \mathrm{~cm}^{3}$ & $1,11 \mathrm{~b}$ & $0,85 \mathrm{~b}$ & $0,37 \mathrm{a}$ & $0,43 \mathrm{a}$ & $1,48 \mathrm{~b}$ & $1,28 \mathrm{a}$ \\
$7 \mathrm{~cm}^{3}$ & $0,56 \mathrm{c}$ & $0,33 \mathrm{c}$ & $0,23 \mathrm{~b}$ & $0,19 \mathrm{~b}$ & $0,79 \mathrm{c}$ & $0,52 \mathrm{~b}$ \\
\hline $\mathrm{r}^{2}$ & 0,69 & 0,62 & 0,46 & 0,47 & 0,70 & 0,61 \\
\hline $\mathrm{CV}$ & 41,41 & 36,86 & 31,49 & 35,24 & 35,85 & 33,46 \\
\hline$p$ value & $<0,0001$ & $<0,0001$ & 0,0002 & 0,0002 & $<0,0001$ & $<0,0001$ \\
\hline
\end{tabular}

Diferentes letras indican diferencias significativas según test de LSD Fisher $(\mathrm{p} \leq 0,05)$

Cuadro 5. Promedio del peso seco de la parte aérea, raíces y total de las plántulas al trasplante, obtenidos para los diferentes volúmenes de celdas en los dos ciclos de producción.

\begin{tabular}{|c|c|c|c|c|c|c|}
\hline \multirow[t]{2}{*}{ Volumen } & \multicolumn{2}{|c|}{$\begin{array}{l}\text { Peso seco parte aérea } \\
\text { (g) }\end{array}$} & \multicolumn{2}{|c|}{$\begin{array}{c}\text { Peso seco raíces } \\
\text { (g) }\end{array}$} & \multicolumn{2}{|c|}{$\begin{array}{c}\text { Peso seco total } \\
(\mathrm{g})\end{array}$} \\
\hline & $37 \mathrm{dds}$ & $49 \mathrm{dds}$ & $37 \mathrm{dds}$ & $49 \mathrm{dds}$ & $37 \mathrm{dds}$ & $49 \mathrm{dds}$ \\
\hline $24 \mathrm{~cm}^{3}$ & $0,14 \mathrm{a}$ & $0,16 \mathrm{a}$ & $0,02 \mathrm{a}$ & $0,05 \mathrm{a}$ & $0,16 \mathrm{a}$ & $0,21 \mathrm{a}$ \\
\hline $13 \mathrm{~cm}^{3}$ & $0,08 \mathrm{~b}$ & $0,12 \mathrm{~b}$ & $0,02 \mathrm{a}$ & $0,05 \mathrm{a}$ & $0,10 \mathrm{~b}$ & $0,17 \mathrm{a}$ \\
\hline $7 \mathrm{~cm}^{3}$ & $0,05 \mathrm{c}$ & $0,05 \mathrm{c}$ & $0,01 \mathrm{~b}$ & $0,03 \mathrm{~b}$ & $0,06 \mathrm{c}$ & $0,08 \mathrm{~b}$ \\
\hline $\mathrm{r}^{2}$ & 0,66 & 0,54 & 0,42 & 0,43 & 0,66 & 0,54 \\
\hline $\mathrm{CV}$ & 33,91 & 39,22 & 23,95 & 34,66 & 30,04 & 34,52 \\
\hline$p$ value & $<0,0001$ & $<0,0001$ & 0,0007 & 0,0005 & $<0,0001$ & $<0,0001$ \\
\hline
\end{tabular}

Diferentes letras indican diferencias significativas según test de LSD Fisher $(\mathrm{p} \leq 0,05)$ 
en celdas de $7 \mathrm{~cm}^{3}$ tuvo no solo una implicancia significativa sobre el crecimiento de las raíces sino también repercutió en el crecimiento de la parte aérea de las plántulas. Esto afirma que un pequeño espacio disponible para las raíces, dificulta el normal suministro de recursos para garantizar un óptimo crecimiento y desarrollo de las plántulas; en cambio, a medida que aumenta el volumen de celda aumenta el área foliar y la biomasa aérea de las plántulas (CANTLIFFE, 1993).

Los resultados alcanzados condicen con los obtenidos por Resende et al. (2003), que al evaluar plántulas de lechuga, obtuvieron valores promedios superiores en biomasa total a medida que aumentaron los volúmenes de celdas de $7 \mathrm{~cm}^{3}$ a $13 \mathrm{~cm}^{3}$ y $24 \mathrm{~cm}^{3}$, de igual manera, Machado et al. (2008) recomiendan el uso de volúmenes de 24 $\mathrm{cm}^{3}$ en la producción de plántulas para el mismo cultivo.

En síntesis, utilizar bandejas de germinación con celdas de $24 \mathrm{~cm}^{3}$ permitió obtener plántulas de lechuga mantecosa de mejor calidad en comparación con los demás tratamientos, para ser trasplantadas en períodos de tiempo que oscilaron entre 37 a 49 días después de la siembra para las condiciones de estudio.

Disponer de plántulas con un adecuado desarrollo aéreo y radicular, aumentará las probabilidades de éxito en la implantación al sobrellevar de mejor manera el estrés que implica la operación de trasplante, ésta afirmación adquiere más significancia aún cuando el cultivo se realiza en campo, a diferencia de un trasplante en invernadero donde las condiciones de mayor temperatura, humedad y escasa presencia de viento contribuyen a reducir el efecto del estrés.

\section{Rendimiento}

La cosecha se efectúo a los 127 y 105 días después del trasplante para el ciclo 1 y 2 respectivamente. Los resultados obtenidos mostraron diferencias estadísticas significativas entre los tratamientos, alcanzando valores de rendimiento muy superiores principalmente al contrastar las plántulas provenientes de celdas de $24 \mathrm{~cm}^{3}$ y $7 \mathrm{~cm}^{3}$. Rendimientos intermedios se lograron en el tratamiento de $13 \mathrm{~cm}^{3}$ (Cuadro 6).

Los resultados obtenidos coinciden con los encontrados en López (2002); Resende et al. (2003); Seabra et al. (2002) y Juri et al. (2009), quienes establecieron que las plantas provenientes de plántulas crecidas en bandejas de germinación con mayor volumen de celdas presentaron un mejor desempeño en campo y rendimiento total. Según lo expuesto por Nesmith y Duval (1998) y Bennett (2010), la restricción al crecimiento radicular en la etapa de crecimiento de las plántulas afecta el normal desarrollo y crecimiento posterior. Sin embargo a diferencia de los resultados obtenidos por Silva y Katherine (2004), si se lograron diferencias en rendimiento a la cosecha, a partir de plántulas obtenidas en bandejas de diferentes volúmenes.

Cuadro 6. Rendimientos a cosecha en peso fresco y seco $\left(\mathrm{t}^{\mathrm{h}} \mathrm{a}^{-1}\right)$ obtenidos para los diferentes volúmenes de celdas en los dos ciclos de producción.

\begin{tabular}{ccccc}
\hline \multirow{2}{*}{ Volumen } & \multicolumn{2}{c}{ Rendimiento } & \multicolumn{2}{c}{$\begin{array}{c}\text { Rendimiento } \\
\text { Peso seco }\left(\mathrm{t} \mathrm{ha}^{-1}\right)\end{array}$} \\
\cline { 2 - 5 } & \multicolumn{2}{c}{ Ciclo 1} & Ciclo 2 & \multicolumn{2}{c}{ Ciclo 1 } & Ciclo 2 \\
\hline $24 \mathrm{~cm}^{3}$ & $37,78 \mathrm{a}$ & $33,83 \mathrm{a}$ & $3,54 \mathrm{a}$ & $2,10 \mathrm{a}$ \\
$13 \mathrm{~cm}^{3}$ & $32,78 \mathrm{~b}$ & $22,31 \mathrm{~b}$ & $3,55 \mathrm{a}$ & $1,47 \mathrm{~b}$ \\
$7 \mathrm{~cm}^{3}$ & $25,13 \mathrm{c}$ & $13,29 \mathrm{c}$ & $2,76 \mathrm{~b}$ & $0,81 \mathrm{c}$ \\
\hline $\mathrm{r}^{2}$ & 0,43 & 0,86 & 0,24 & 0,82 \\
\hline $\mathrm{CV}$ & 19,18 & 15,21 & 20,45 & 17,51 \\
\hline$p$ value & $<0,0001$ & $<0,0001$ & 0,0002 & $<0,0001$ \\
\hline
\end{tabular}

Diferentes letras indican diferencias significativas según test de LSD Fisher $(\mathrm{p} \leq 0,05)$ 


\section{CONCLUSIONES}

- El aumento del volumen de celdas permitió obtener plántulas de mayor número de hojas, altura y peso de la parte aérea; sin embargo, no se encontraron diferencias significativas respecto a longitud y peso de raíces al comparar celdas de 24 y $13 \mathrm{~cm}^{3}$. El rendimiento del cultivo a cosecha aumentó a medida que las plántulas se obtuvieron en bandejas con celdas de mayor volumen, por lo tanto, utilizar bandejas con celdas de $24 \mathrm{~cm}^{3}$ para la producción de plántulas de lechuga mejoraría significativamente los rendimientos en trasplantes realizados en campo.

\section{REFERENCIAS BIBLIOGRÁFICAS}

ADESUR. Asociación interinstitucional para el sur de Córdoba. Plan director. Secretaría técnica de Adesur. Universidad Nacional de Río Cuarto. Córdoba. Argentina. 99p.1999.

BENNETT, M.A. Calidad de trasplantes de hortalizas. American Vegetable Grower. Universidad Estatal de Ohio, 2010. Disponible en: $\quad<$ http://www.hortalizas.com/articulo/4465/ calidad-de-trasplantes-de-hortalizas $>$. Acceso el: 25/06/2015.

CANTERO GUTIÉRREZ, A.; BRICCHI, E.M.; BECERRA, V.H.; CISNERO, J.M.; GIL, H. Zonificación y descripción de las tierras del departamento de Río Cuarto, Córdoba, Argentina 1986. 78p..

CANTLIFFE, D.J. Pre- and postharvest practices for improved vegetable transplant quality. HortTechnology, v.3, n.4, p.415-418. 1993.

COFECYT. Debilidades y desafíos tecnológicos del sector productivo: hortalizas de hojas verdes (acelga, espinaca, lechuga). La Pampa y Santa Cruz, 2008. Disponible en: $<$ http://www. cofecyt.mincyt.gov.ar/pcias_pdfs/santa_cruz/ UIA hortalizas de hoja 08.pdf.> Acceso el: 12/06/2015.
DI RIENZO, J.A.; CASANOVES, F.; BALZARINI, M.G.; GONZALEZ L., TABLADA, M.; ROBLEDO, C.W. InfoStat versión 2014. Grupo InfoStat, FCA, Universidad Nacional de Córdoba, Argentina. URL. Disponible en: $<\underline{\text { http: } / /}$ www.infostat.com.ar $>$ Acceso el: 03/06/2015.

JURI, M.S.; RICARDES, M.G.; MINERVINI, M.G.; FERNÁNDEZ, S.; ALVAREZ, M.E.; GIULIANO, M.S.; VILLAGRA, E.L. Evaluación de efectos del tamaño del contenedor sobre lechuga (Lactuca sativa L.) en etapas de pretrasplante y cosecha. XXXIII Congreso Argentino de Horticultura. Libro de resúmenes... Rosario Argentina, p.313, 2009.

LESKOVAR, D.I. Producción y ecofisiología del trasplante hortícola. Buena Vista, Saltillo, Coahuila. Curso. p.1-24. 2001.

LESKOVAR, D.I.; CANTLIFFE, D.J.; STOFFELLA, P.J. Root growth and rootshoot interactionin transplants and direct seeded pepper plants. Journal Experimental Botany, v.30, p.249-354, 1990.

LÓPEZ, M. Influencia del volumen de contenedores de almácigo en el crecimiento y desarrollo de zapallo italiano (Cucurbita pepo L.). Taller de licenciatura, Ingeniería. Agrícola. Universidad Santo Tomás. Facultad de Agronomía. Santiago, Chile. 55p., 2002.

MACHADO, A.Q.; NETO, R.H.B.; MACHADO, A.Q.; COELHO, L.C. Produção de mudas de alface crespa em diferentes tipos de bandejas, em Várzea Grande-MT. Horticultura Brasileira, v.26, n.2, p.1036-1041. 2008.

MARQUES, P.A.; BALDOTTO, P.V.; SANTOS, A.C.; DE OLIVEIRA, L. Qualidade de mudas de alface formadas em bandejas de isopor com diferentes números de células. Horticultura Brasileira, v.21, n.4, p.649-651, 2003.

MELLONI, C. Bandejas de germinación. 2012. Disponible en: <http://www.ingcarluccio.com.ar/ 
base.html>. Acceso el: 14/08/2014.

MENEZES, F.O.G.; FERNANDES, H.S.; MAUCH, C.R.; SILVA, J.B. Caracterização de diferentes substratos e seu desempenho na produção de mudas de alface em ambiente protegido. Horticultura Brasileira, v.18, n.3, p.164-170, 2000.

MINAMI, K. Produção de mudas de alta qualidade em horticultura. São Paulo: T. A. Queiroz, 1995. 13p.

MODOLO, A.J.; NETO, T. Desenvolvimentos de mudas de quiabeiro (Abelmoschus esculentus (L). Moench) em diferentes tipos de bandeja e substrato. Scientia Agrícola, v.56, n.2, p.377-381, 1999.

NESMITH, D.S.; DUVAL, J.R. The effect of container size. HortTechnology, v.8, n.4, p.495498, 1998.

RESENDE, G.M.; YURI, J.E. ; MOTA, J.H.; SOUZA, R.J. ; FREITAS, S.A.C.; RODRIGUES JUNIOR, J.C. Efeitos de tipos de bandejas e idade de transplante de mudas sobre o desenvolvimento e produtividade de alface americana. Horticultura
Brasileira, Brasília, v.21, n.3, p.558-563, 2003.

SANTI, A.; CARVALHO, M.; CAMPOS, O.R.; DA SILVA, A.F.; DE ALMEIDA, J.; MONTEIRO, S. Ação de material orgânica sobre a produção e características comerciais de cultivares de alface. Horticultura Brasileira, v.28, p.87-90, 2010.

SEABRA, S.; GADUM, J.; VILLANI, P.L.F.; GONÇALVES, T.L.M.; DA SILVA, N.; GOTO, R. Produção de alface americana em função de tipos de bandeja. UNESP-FCA, Departamento de Produção Vegetal. Horticultura, Botucatu-SP, Brasil, 2002.

SILVA, S.; KATHERINE, R. Evaluar de tres tamaños de celdillas de bandejas de speedling sobre la calidad de las plántulas y la producción de una variedad de lechuga (Lactuca sativa L.) tipo escarola. Tesis en Ingeniería Agrícola. Universidad Católica de Valparaíso, Chile, 89p., 2004.

VAVRINA, C.S. 1995 An introduction to the production of containerized vegetable transplants. Univ. of Florida, Gainesville, Coop. Ext. Serv.(Bul. 302). 